\title{
Paradojas de la inculturación del evangelio en la política
}

\author{
Jung Mo Sung, \\ Sao Paulo, Brasil.
}

\section{1. ¿Tenemos una bnena nueva en el campo político?}

"¿Tiene la fe una 'palabra esencial' que decir en el campo político?"I. Esta es, en nuestra opinión, la pregunta fundamental cuando se debate la participación de los cristianos en la política y la relación entre evangelización y mundo político2. Decimos que es fundamental porque es la pregunta-respuesta sobre la que se basa toda la discusión y, por ello, es la pregunta más importante hoy.

Si la respuesta es un no, olvidemos el asunto y limitemos la cuestión de la evangelización y de la inculturacion a otros campos de la vida personal y social (por ejemplo, al ámbito de lo privado o de las culturas negra, indígena, urbana, etc.). Si la respuesta es un sI, ¿cuál es, entonces, esa palabra? El problema, por lo demás, no es así de simple. Dejando aquí de lado la posición dualista de los que niegan todo tipo de relación entre evangelización y polf́ica, vearnos ahora algunas cuestiones que surgen cuando, en nombre de la opción por los pobres o del Dios de la vida, asumimos explícilamente que existe una relación entre evangelización y política.

Un texto de Clodovis Boff, "Los cristianos y la cuestión partidista"3, desencadenó un rico debate sobre el tema y se llego al siguiente punto de acuerdo:

Por lo tanto, hay acuerdo sobre la "articulación (pastoral) de los cristianos militantes", pero no sobre la articulación (polftica) de los militantes cristianos. De hecho, por lo que toca a esta última - la articulación políticaexiste escepticismo e incluso abierto desacuerdo. Se teme que represente el resurgir de la idea de "cristiandad", ahora bajo una nueva forma4.

La articulación pastoral de los militantes cristianos tendría, entonces, como objetivo "profundizar la experiencia y la reflexión de la fe asl como preparar mejor a los cristianos para la préctica político-partidaria"s. 
Esto significa que la fe cristiana tiene algo que decir a los cristianos que participan en el mundo polftico. Pero el problema que surge es en qué consiste ese preparar mejor a los cristianos para la práclica político-partidaria. Y aquí existen dos posibles respuestas. Una es que esta preparación se restringiría al campo ético-ulópico, correlativo a la fe cristiana. La otra es que la preparación incluirfa también las mediaciones políticas. Según esto, la primera alternativa no es más que una mera repetición del objetivo de "profundizar la experiencia y la reflexión de fe", lo cual es insuficiente; mientras que la segunda nos lleva a los problemas actuales en torno a la articulación política de los cristianos.

Para hablar con precisión, al hablar de articulación política se está presuponiendo la existencia de un proyecto político y las mediaciones necesarias, en torno al cual se articulan militantes o grupos. Y si la formación-articulación pastoral de los cristianos incluye mediaciones políticas, ya está implícito -al menos inconscientemente- un proyecto político. $\mathrm{Y}$ cuando se presupone un proyecto político, están dadas las condiciones para pensar en una articulación política de los cristianos, abierta también a los no cristianos.

Existe, sin embargo, como hemos dicho, escepticismo y reacciones en contra de un proyecto político cristiano, porque está considerado como una nueva forma de cristiandad, pero esto desvía la atención de lo que ocurre en la práctica: no existen mecanismos concretos que preparen a los cristianos para la práctica política -de lo cual se quejan muchos teólogos y militantes cristianos.

Con esto llegamos a lo que nos parece ser el fondo de la cuestión. Por una parte, no aceplamos la separación radical entre la fe cristiana y las cuestiones políticas. Pero como, por otra, no queremos correr el riesgo de una nueva cristiandad, no discutimos desde la fe cristiana proyectos políticos concretos ni sus mediaciones. De esta forma, la fe cristiana y las mediaciones pastorales quedan de nuevo disociadas de la racionalidad y de las prácticas polf́ticas y se debilita todavía más la preparación de los cristianos que van a militar en la polf́ica. Y como no se puede participar en política sin mediaciones, lo que ocurre en la práctica es que se utilizan mediaciones de algún tipo de tradición o de inspiración marxista (por supuesto entre los militantes de izquierda a los que nos estamos refiriendo), mediaciones éstas que son acepladas sin mucha critica, sea a partir de la fe cristiana, sea a partir de otras teorias.

Una consecuencia de todo esto serfa que la fe cristiana no tiene nada especlfico que decir en el campo político. Es cierto que ofrece una palabra para los cristianos actuantes en la política, pero sólo para ellos, no para el campo polf́tico "en sí" ni para las diversas mediaciones polĺticas. En esto seguimos dependiendo de tradiciones político-téricas como la marxista o la liberal, como si la fe cristiana sirviese sólo para la motivación personal -de nuevo restringida al campo privado- para que los cristianos entren y perseveren en la lucha política. 
Algunos intentan recuperar la importancia social de la religión, afimnando que la posición social y política de las iglesias cristianas es importante en América Latina debido a la religiosidad del pueblo latinoamericano. Pero éste es sólo un aspecto coyuntural de la realidad, que no vale para los parses donde el cristianismo es minoritario. La pregunta de fondo sigue siendo, pues, si el cristianismo tiene o no una buena nueva para los pobres también en el campo político, si el cristianismo tiene algo que contribuir en el actual debate sobre alternativas para América Latina en la búsqueda de un nuevo paradigma en el campo político y económico que supere el actual estado de las cosas.

\section{Cristiandad: ¿un peligro real?}

Generalmente, el debate sobre la contribución del cristianismo a la política se estanca en el "peligro" de una nueva cristiandad. Ese fue y es uno de los argumentos más fuertes contra la articulación política de los cristianos y el debate sobre la relación entre proyectos políticos y fe cristiana. Pero, ¿qué es la cristiandad?, ¿en qué consiste ese peligro?

Pablo Richard, en su libro Muerte de las cristiandades y nacimiento de la Iglesia, definió "la cristiandad como una forma determinada de relación entre la Iglesia y la sociedad civil, relación cuya mediación fundamental es el Estado. En un régimen de cristiandad, la Iglesia procura asegurar su presencia y expandir su poder en la sociedad civil, utilizando ante todo la mediación del Estado"6.

Otro variante del concepto de cristiandad se da en el equivoco de identificar o confundir a la Iglesia con el partido o el Estado. Es la tentación "de la reconfesionalización del Estado o de lo político"7, y ésta me parece ser la concepción de cristiandad que está siendo más utilizada en el actual debate -quedando claro que se procura evitar, con razón, cualquier forma de cristiandad.

Pero la pregunta que surge es si el peligro es tan real que justifique "paralizar" el debate, a partir de la fe cristiana, sobre los proyectos y mediaciones poIf́cicas. ¿Hay hoy viabilidad histórica para una cristiandad — sea de "derecha" o de "izquierda" - como la de la edad media o la del tiempo de la colonia?

Hacer futurologra es siempre peligroso, pero nos debemos arriesgar a decir una palabra sobre la posibilidad de nuevas cristiandades. Cristiandad $\longrightarrow$ la religión como el fundamento o la principal forma de legitimación del poder constituido- es un fenómeno de las sociedades pre-modernas. Los gobernantes de las sociedades tradicionales necesitan ser representantes de la religion "oficial" o hacer una alianza con el grupo dirigente de la religión mayoritaria. Esto es asf porque en este lipo de sociedades la religión es la instancia última del fundamentu de todo orden social. La cristiandad no es, pues, fruto solamente del poder de la Iglesia, sino tambien de una necesidad social. El tipo de cristiandad estudiada por Pablo Richard es el túpico de la fase de transición de una sociedad pro-moderna a una moderna. 
Las sociedades modernas, sin embargo, se caracterizan por lo que muchos llaman "secularización". Este es un concepto bastante discutido hoy, principalmente desde que diversos estudios muestran la dimensión religiosa y sacrificial de la modernidad8, pero lo utilizamos para mostrar un cambio fundamental en el campo de la política y de la religión.

La secularización traslada a la política la función integradora que anteriormente desarrollaba la religión. $\mathrm{Si}$ antes era la religión la que consagraba una instancia última en la que se fundaban todas las manifestaciones del orden establecido, ahora se atribuye a la política un lugar privilegiado en la producción del orden social. La sustitución del fundamento divino por el principio de la soberanía popular instituye la centralidad de la política en un doble sentido: (a) en cuanto acción consciente de la sociedad sobre sí misma; y (b) representación de la sociedad en cuanto orden colectivo9.

Debido a esta modificación fundamental, la cristiandad, además de ser un equívoco teológico, se convierte ahora, en el mundo moderno, en un proyecto llamado al fracaso. A lo sumo, la religión puede ser utilizada como instrumento de apoyo secundario a cambio de algunos beneficios institucionales. La contraprueba es que el fundamentalismo islámico sólo consigue lọgrar su intento en países de cultura marcadamente pre-moderna 10 .

\section{El desafío de unificar la razón, la fe y la operacionalidad}

Anunciar la buena nueva de Jesús al y en el campo político no es una tarea fácil, sino todo lo contrario. Si el acompañamiento pastoral de los cristianos que actúan en política ya está siendo una tarea difícil, cuánto más lo será inculturar y anunciar el evangelio en un mundo marcado por el desencanto y la racionalidad instrumental, como es el de la política moderna. Algunos pueden llegar incluso a afirmar la "imposibilidad" de emitir "juicios absolutos" sobre una realidad tan dinámica y contradictoria como la política. Y aquí vale recordar las palabras de Juan Luis Segundo en su importante artículo "Capitalismo-Socialismo: crux theologica", escrito en los inicios de la teología de la liberación:

Toda teología que se niega, pues, a hacer un juicio teológico, esto es, invocar la palabra de Dios, acerca de una realidad política, so pretexto de que la ciencia no puede demostrar lo que será el futuro (...) se aparta claramente de la función proféticall.

Ahora que hablamos tanto de evangelización e inculturación, no estará de más recordar que hay una diferencia cualitativa entre la inculturación del evangelio en una cultura indígena o negra y la inculturación en el mundo político. En la inculturación del evangelio en el mundo indígena, por ejemplo, a pesar de todas las dificultades, se trata del diálogo con un mundo similar: un mundo que tiene como su fundamento la religión. Se puede establecer así un diálogo interreligioso. 
El mundo de la política modema, por el contrario, no se fundamenta ya en la religión o en la tradición, sino en una creencia en la validez de un estatuto legal, fundado en reglas establecidas racionalmente. Con ese mundo no se establece un diálogo interreligioso porque los argumentos de la tradición o de la autoridad religiosa no son ya aceptados en el campo político. Esto supone el desafío de proclamar un mensaje que, por una parte, sea reconocido como buena nueva para los pobres y, por otra, que sea al mismo tiempo un discurso razonable, es decir, justificable por la razón y no solamente por el argumento de autoridad religiosa, aunque sin perder su característica de discurso religioso. Es el desafío de pronunciarnos con un discurso religioso que sea al mismo tiempo también racional.

Estamos hablando, pues, de una inculturación tal vez más radical aún que la que hay que llevar a cabo en relación al mundo indígena o a una cultura aún fuertemente marcada por la tradición y por la religión. Estamos tratando de relacionamos con un mundo que, además de no aceptar ya el argumento religioso, esı́á marcado esencialmente por el conflicto, por la disputa del poder y por la búsqueda de la operacionalidad. Un mundo donde cualquier objetivo exige conquistar y mantener el poder, y de tal manera que mantener el poder acaba siendo visto como un bien en sí mismo que hay que proseguir.

Maquiavelo, considerado el inaugurador de la ciencia política moderna porque investigó los mecanismos de poder realmente existentes y no lo que debiera ser, distinguió la élica moral de la élica política. La primera, según él, está preocupada con los fines, cómo ser bueno, y la ética política se ocupa de cómo hacer para llegar a mantenerse en el poder:

Mucha gente imaginó repúblicas y principados que nunca vieron, ni jamás fueron reconocidos como verdaderos. Existe tanta diferencia entre cómo se vive y el modo según el que se debería vivir, que quien se preocupa por lo que se debería hacer en vez de lo que se hace aprende antes su ruina propia que el modo de preservarse; y un hombre que quiera hacer profesión de bondad es natural que se arruine entre tantos que son malos. Así, para mantenerse, le es necesario al príncipe, que aprenda a poder ser malo12.

Es claro que debemos criticar esta visión meramente instrumental de la política y de mantener el poder. Pero no podemos dejar de reconocer que no se puede pensar y hacer polf́tica sin realismo histórico.

En resumen, la evangelización del mundo político, además de ser un anuncio racional, debe contener propuestas operacionalizables, y no solamente juicios y deseos absolutos, históricamente inviables 13 .

\section{Desafíos que vienen de la política}

La buena nueva es, o debe ser, una respuesta a los problemas y desafíos concretos que vienen de la realidad. Una doctrina que "viene del cielo" no siempre 
responde a las preguntas que nacen de la vida concreta. Esto significa que, antes de anunciar la buena nueva, debemos escuchar primero las preguntas y los desafíos de hoy. Y después, procurar anunciar las buenas nuevas que sean al mismo tiempo fieles a la tradición bíblica y que sean noticias verdaderamente nuevas y buenas para los pobres de hoy.

Lo primero es el gran desafío para aquellos que asumen la política desde la perspectiva de los pobres y de los excluidos de América Latina y supone la superación de la grave crisis económica y social que vivimos desde hace más de una década. La década perdida, que se inició con la crisis de la deuda externa en 198214, agravó aún más los problemas económicos y sociales de América Latina (por ejemplo, el desempleo, la concentración de la renta, la inflación) además de otras dificultades para la consolidación de la democracia.

La superación de esta crisis económica y social no es solamente un problema económico o técnico. Si es verdad que necesitamos un nuevo modelo de desarrollo económico volcado hacia las necesidades de las mayorías pobres, también es verdad que la solución de la crisis exige una decisión política. Y esto supone, como dice Lechner, "mecanismos institucionales para la elaboración de opciones y toma de decisiones. Vale decir: no hay proyecto sin pacto. La solución de la crisis económica y la construcción del sistema democrático deben ser abordados como procesos simultáneos" 15 .

Esta construcción de un nuevo sistema democrático y de un nuevo pacto supone la superación de la "lógica de la guerra" en la política. La lógica que dice, por ejemplo, "la distinción específicamente política a la que pueden reportarse las acciones y los motivos políticos es la discriminación entre amigo y enemigo"16. La lógica de la aniquilación del enemigo y de la abolición de diferencias es la lógica que rige las dictaduras, sean de derecha o de izquierda.

Pacto no significa aquí un simple acuerdo entre las élites que buscan algunas pequeñas reformas. Estamos hablando de un nuevo pacto, un nuevo consenso en la sociedad, en torno a un proyecto político y económico capaz de superar nuestros graves problemas sociales. En otras palabras, estamos hablando de lo que debe ser, al mismo tiempo, causa y resultado de una revolución en el actual orden establecido y en la estructura mental de la sociedad. Sin ese nuevo pacto sólo podemos pensar en cambios profundos a través de una dictadura, de imposición por la fuerza.

Uno de los problemas de formular un pacto sobre un nuevo proyecto que integre en la sociedad a los excluidos y busque un desarrollo sostenido para toda la nación es lo que Galbraith ha llamado "la cultura del conformismo" de nuestra élites y sectores medios 17 . La primera característica de esta cultura es que aquellos que componen el grupo de los satisfechos con el actual orden económico-social no estarían haciendo otra cosa que obtener lo que justamente merecen. 
Luego, ya sea que la buena fortuna es merecida, ya sea que es una recompensa al mérito personal, no hay — según ellos- justificación para ningún tipo de acción o proyecto político que pueda perjudicarlos, reduciendo su nivel de consumo. La segunda caracteristica importante es su actitud frente al tiempo. Como los costos de las medidas para superar la crisis pueden recaer sobre las élites, éstas prefieren la inercia polílica hoy a las medidas protectoras del mañana. Como dice Galbraith. "la serena teología del laissez faire (dejar hacer) sostiene que al final todo acabará resolviéndose de la mejor manera posible"18. Una tercera característica que nos interesa destacar es "la tolerancia ante las grandes diferencias de la renta... Lo que ocurre aquí es la observancia fiel de una convicción general y bastante plausible: el precio para prevenir cualquier disminución de la propia renta es tolerar que crezca la renta de los demás"19.

Esta cultura del conformismo de los que están bien integrados en el mercado genera un inmovilismo político o sólo permite cambios que sirven para que todo siga igual.

Muchos grupos de izquierda, por su lado, presentan otro tipo de problemas que dificulta la construcción de un nuevo proyecto y el pacto en tomo a él. Probablemente debido a la urgencia de los problemas sociales y a una profunda indignación ética, muchos militantes y grupos de izquierda (incluidos cristianos y no cristianos) exacerban el voluntarismo y se acercan a un "mesianismo secularizado". Después de la tradición judeo-cristiana, el romanticismo presente en el pensamiento de Marx ${ }^{20}$ se ha convertido también, en cierta forma, en vehículo del mesianismo. Filosófica y políticamente ello ha quedado plasmado en la idea de que "la clase obrera es el sujeto que rescalará la historia de su particularidad, y por tanto quien la representa encarna una universalidad que falta a los demás actores de lo político"21. Quien se cree representante de lo universal también pretenderá estar exento de las reglas generales de la gestión pública, y los medios utilizados, cualesquiera que sean, quedan absueltos de culpa porque producen la emancipación de la humanidad.

Además del problema ético que esto acarrea, una autoimagen mesiánica genera también distorsiones en la lectura de la realidad polf́tica. Mesiánicos y voluntaristas siempre tienden a sobreestimar su capacidad de intervención política y a subestimar las fuerzas del adversario. $Y$ esto para no hablar de dogmatismo.

Un marxismo así interpretado "no sólo concibe la política como guerra, sino que la concibe también como ciencia. De ahí resulta una guerra que se basa en certezas de orden cienúfico"22. Así, no es posible pensar en pacto, mucho menos en tolerancia con los contrarios, con los adversarios (que son vistos como enemigos a ser extirpados), todo lo cual es presupuesto de la democracia.

Una política asI concebida reproduce miméticamente la lógica sacrificial ca- 
pitalista que quiere combatir. La "guerra santa" de la emancipación (liberación) definitiva exige sacrificios de los militantes y justifica los sacrificios que se imponen a la sociedad en la llamada fase de transición para el reino de la libertad23.

Esta concepción mesiánica de grupos de izquierda presupone la posibilidad histórica de una sociedad sin Estado y sin relaciones mercantiles, la posibilidad del reino de la libertad en plenitud en la historia humana como fruto de la obra humana -concepción bastante presente en las comunidades eclesiales de base y en las pastorales de frontera, como la de la tierra o la obrera. El problema es que no es factible. Transciende la capacidad humana24. El propio Marx reconoce en su madurez que

el reino de la libertad sólo comienza, de hecho, donde cesa el trabajo determinado por la necesidad y por la adecuación a finalidades externas; por tanto, por la propia naturaleza del asunto, esto transciende a la esfera de la producción material propiamente dicha. Así como el salvaje tiene que luchar con la naturaleza para satisfacer sus necesidades, para mantener y reproducir su vida, así también el civilizado tiene que hacerlo en todas las formas de sociedad y bajo cualquier modo de producción posible 25 .

En cualquier modo posible de producción, los grupos humanos necesitan satisfacer sus necesidades y para eso necesitan resolver todos los problemas que aparecen en la división social del trabajo. Podemos tener más libertad, pero no podemos extinguir el reino de la necesidad e implantar el reino de la libertad en plenitud. La tradición cristiana asumió esta realidad con la dialéctica "ya, pero todavía no" (historia y escatología).

Para la elaboración de un proyecto alternativo viable necesitamos superar el "conformismo" de las élites y el "mesianismo" de los grupos de izquierda. Y además, hay que enfrentar otro problema. La validez de un pacto-"contrato" remite a una normatividad externa a él. No tenemos en nuestro país (ni en otros de América Latina) una norma fundamental o un consenso básico sobre el cual podamos fundar un reconocimiento, por parte de todos, de los procedimientos institucionales que busquen la creación de un nuevo orden social y político. Por consiguiente, necesitamos elaborar el fundamento normativo por medio del cual estas acciones políticas adquieran sentido.

\section{Desafíos a la teología}

¿Qué quiere decir que no es posible una sociedad sin Estado? Max Weber definió el Estado contemporáneo "como una comunidad humana que, dentro de los límites de determinado territorio (...), reivindica el monopolio del uso legitimo de la violencia física", y "el Estado consiste en una relación de dominación del hombre sobre el hombre, fundada en el instrumento de la violencia legítima (es decir, sobre la violencia considerada como legítima). El Estado sólo puede 
existir, por tanto, bajo la condición de que los hombres dominados se sometan a la autoridad continuamente reivindicada por los dominadores" 26.

Una de las características centrales del Estado es, pues, el monopolio de la violencia legftima o el uso de la coerción en nombre de la legalidad. La imposibilidad de una sociedad sin Estado significa, entonces, la paradoja de luchar por la conquista del poder del Estado buscando la construcción de una sociedad sin dominación (o con menos dominación). Significa el reconocimiento de la paradoja de la condición humana y, en el caso del Estado, crear mecanismos de control del propio Estado para el fortalecimiento de la democracia y de la sociedad civil.

La lucha por la conquista del poder e influencia en el Estado es la condición para la superación del actual orden económico-socio-político hacia un orden mas justo e igualitario. Pero, al mismo tiempo, la conquista del poder es, por sí misma, la posibilidad para ejercer dominación. Esa tensión es inevitable y depende de nosotros construir mecanismos que controlen las innumerables posibilidades de la mala utilización del poder del Estado, no importando la ideologla de los gobernantes. Ninguna persona, ningún grupo político, por más santos y honestos que sean, están inmunes a las contradicciones y paradojas del poder. Pero, por otra parte, no luchar en el campo político en nombre de estas contradicciones - tentación frecuente en los grupos que buscan la "pureza espiritual"- es un grave error.

Si esto es verdad y si es imposible superar totalmente estas contradicciones al nivel del Estado y de la política, hay que tener cuidado cuando presentamos, por ejemplo, la santísima Trinidad - la comunidad perfecta- como el modelo de sociedad que queremos 27 . La Trinidad debe ser sin duda modelo de comunidad. Pero en términos de macro-sociedad necesitamos tener claro que la utopla de una comunidad perfecta - sin dominadores, en comunión plena- no es humanamente posible. Sirve de horizonte que da sentido a nuestras luchas, pero como todo horizonte sabemos que es imposible alcanzarlo.

Esto quiere decir que no podemos pasar del nivel de las relaciones "micro", comunitario, a relaciones "macro", política-Estado, de modo lineal. Necesitamos desarrollar urgentemente una visión teológico-cristiana de la política que posibilite una contribución eficaz en la elaboración de un nuevo fundamento nomativo -ético y político- que busque la implantación de un nuevo proyecto económico y pollitico.

En este momento de crisis de la razón moderna y de la propia modernidad, la búsqueda de un nuevo fundamento nomativo nos remite al problema de la posibilidad y de los límites del proyecto de emancipación de la humanidad. Debemos evitar, en este punto, el optimismo exagerado de la modernidad y el pesimismo exacerbado de la post-modernidad neoliberal. Tanto la afirmación como la negación absoluta de la posibilidad de emancipación humana, así como 
la visión que defiende posibilidades dentro de unos límites, presupone la referencia al Absoluto. Como dice Manfredo A. Oliveira: "la referencia al Absoluto es condición última de posibilidad del proceso de emancipación de la humanidad"28. Siendo esto así, necesitamos asumir de nuevo el desafío de la teología de la liberación desde su inicio: la relación entre política y escatología.

Necesitamos también profundizar el tema del mesianismo. Aceptar como Mesías a un Jesús, que murió en la cruz políticamente fracasado, significa modificar la concepción de mesías como aquel (sea un individuo, sea un grupo político religioso o el mercado) que va a implantar en plenitud el reino de Dios o el reino de la libertad en la historia humana. En este sentido, la teología debe contribuir a su objeto propio -el discernimiento sobre las imágenes de Dios-, criticando las imágenes de dioses sacrificiales subyacentes a la "teología del laissez faire" (J. K. Galbraith) y a las de los "mesianismos secularizados" de los grupos de izquierda vanguardistas y dogmáticos.

Por último, hay que asumir el desafío de "dar razón de nuestra esperanza" (cfr. 1Pe 3,15$)$ también para aquellos que actúan en la política, sean cristianos 0 no. Para eso, necesitamos elaborar mejor la contribución de la fe en la resurrección de Jesús en la construcción de un Brasil y de una América Latina más justa y más humana. Si el núcleo central del cristianismo, la fe en la resurrección de Jesús, no tiene nada o casi nada que decir a nuestro gran desafío que pasa por el campo de la política, alguien podría preguntarnos "para qué sirve entonces el cristianismo hoy".

El cristianismo no es, sin duda, un proyecto político, pero aporta principios fundamentales, parámetros e instrumentos para desenmascarar la subversión de la realidad que lleva a cabo la clase dominante - como por ejemplo, la culpabilización de las víctimas29, la fetichización de las instituciones- y ponerse al servicio de la elaboración e implantación de un nuevo proyecto político. Es cierto, que no debemos caer en la tentación de identificar el cristianismo con un proyecto político concreto; pero, por otro lado, si queremos mantenernos fieles al misterio de la encarnación -el misterio de lo Absoluto que asumió lo relativo, que es la misma historia - debemos correr riesgos y contribuir con lo que es específico del cristianismo al gran desafío de la construcción de una nueva sociedad más humana.

Sabemos que asumir la lucha en el campo político es también sumergirse en las paradojas políticas que vimos antes, pero no hay otro camino. Si queremos ser fieles al Dios de la vida, debemos ser capaces de asumir las contradicciones de la historia y de la condición humana. Toca a las iglesias y a las teologías, en particular a la teología de la liberación, el desafío de presentar al mundo político y a los cristianos actuantes en la política contribuciones significativas, relevantes y operacionalizables a este gran desafío de la construcción de un nuevo proyecto político y económico para Brasil y América Latina. 


\section{Notas}

1. C. Boff, "De vuelta a la cuestión", en Varios, Cristianos: Cómo hacer polftica (Petropolis 1987), p. 157.

2. Estamos utilizando aqú el término "político" en el sentido estricto de la disputa del poder del Estado. Max Weber dice: “ ¿Qué entendemos por polltica? El concepto es extraordinariamente amplio y abarca todas las especies de actividad directiva autónoma (...) Por política entenderemos (...) el conjunto de esfuerzos hechos con vistas a participar del poder o a influenciar la división del poder, sea entre estados, sea en el interior de un único Estado", en Ciencia y Política: Dos vocaciones, (Sao Paulo 41984) pp. 55-56.

3. Artículos reunidos en Varios, Cristianos: Cómo hacer política, El artículo de C. Boff está en las pp. 9-46.

4. C. Boff, "De vuelta a la cuestión", op. cit., p. 150.

5. Ibid, p. 150.

6. Publicado en Paulinas (Sao Paulo 1982), p. 9.

7. Frei Betto, "Los cristianos en la política", en Varios op. cir., p. 59.

8. Ver por ejemplo, H. Assmann-F. Hinkelammert, La idolatría del mercado (Petropolis 1989); F. Hinkelammert, Sacrificios humanos y sociedad occidental (San Jose 1991); J. Santa Ana, El amor y las pasiones (Aparecida 1989); Jong Mo Sung, Dios en una economía sin corazón (Sao Paulo 1992).

9. N. Lechner, Los patios interiores de la democracia: subjerividad y política (Santiago 1990), p. 158.

10. Para una visión de nuevos discursos religiosos que buscan dar una nueva base sagrada a la organización social, ver G. Kepel, La revaneho de Dios (Sao Paulo 1991).

11. Concillium 96 (1974), pp. 776-791.

12. N. Maquiavelo, El Principe (Sao Paulo 1987), p. 63.

13. Sobre hacer teologia en lo modemo y el problema de los horizontes utópicos y factibilidad historica, ver F. Hinkelammert, Crítica de la razón uropica (Sao Paulo 1984;) J. M. Sung, Teología y economía: repensando la $T L$ y las utoplas (Petropolis 1994).

14. A este respecto ver, por ejemplo, J. M. Sung, La idolatría del capisal y la muerte de los pobres (Sao Paulo 1991); Dios en una economía sin corazón...; F. Hinkelammert, La deuda extema de América Latina (Petropolis 1991).

15. Op. cit., p. 33.

16. C. Schmitt, El concepto de lo polfrico (Petrópolis 1992), p. 55.

17. K. Galbraith, La cultura del conformismo (Sao Paulo 1992).

18. Idem, p. 13.

19. Idem, p. 18.

20. Ver por ejemplo, L. Konder, El fururo de la filosofia de la praxis: el pensamiento de Marx en el siglo XXI (Rlo de Janeiro 1992); M. Lowy, Romanticismo y mesianismo (Sao Paulo 1990).

21. R. J. Ribeiro,"Los peligros de lo universal", Teoria y Debare 10 (1990), p. 21.

22. Ibid., p. 25.

23. Sobre la lógica sacrificial ver F. Hinkelammert, Sacrificios humanos y sociedad occidental, op. cit.; sobre el sacrificialismo de los militantes marxistas ver R. J. Ribeiro, "El Bolchevista y el ciudadano romano: ajuste de cuentas", Teoria y Debate, 16 (1991), pp. 46-49. 
24. No lo vamos a desarrollar aquí por falta de espacio. Remitimos a las dos obras ya citadas: F. Hinkelammert, La crítica de la razón utópica; J. M. Sung, Teología y economia: repensando la teología de la liberación y utopias.

25. K. Marx, El Capital, Vol.II, tomo 2 (Sao Paulo 1986), p. 273. Las cursivas son nuestras.

26. Op. cit., pp. 56-57.

27. Por ejemplo, L. Bofr, La Trinidad, la sociedad y lo liberación (Petrópolis 1986).

28. Manfredo Araujo de Oliveira, La filosofia en la crisis de la modernidad (Sao Paulo 1989). La frase citada es de la página 188.

29. A este propósito ver, por ejemplo, H. Assmann, (ed) René Girard con los reblogos de la liberación (Petropolis 1991). 